\begin{tabular}{lllllllllllllllllllllllllllllllll}
\hline$R$ & $E$ & $V$ & I & S & T & A & D & E & E & S & T & U & D & I & O & S & I & N & T & E & R & N & A & C & I & O & N & A & L & E & S
\end{tabular}

EDITORIAL

\title{
Old Boys, New Boys (and Girls)
}

El Instituto de Estudios Internacionales de la Universidad de Chile ha cumplido ya una importante trayectoria en su actividad académica, que se extiende por un período cercano a los cuarenta años.

Tres generaciones de académicos han sido las protagonistas de esta trayectoria. La generación de los fundadores, aquella de quienes les sucedieron y, más recientemente, la de un conjunto de valiosos colaboradores que inician su actividad en el Instituto.

Este número de Estudios Internacionales se ha dedicado a estas tres generaciones, reuniendo trabajos representativos de cada una, que muestran la inagotable creatividad intelectual que caracteriza a la institución.

De allí que se haya concebido bajo el epígrafe común de "Old Boys, New Boys (and Girls)", pues a pesar de las diferencias de edad que puedan separarlos, en realidad todos comparten las mismas inquietudes y revelan una dedicación ejemplar a la investigación universitaria y a la docencia.

Cada una de esta contribuciones es representativa de este aporte, desde aquellas que examinan con agudeza problemas de la política exterior contemporánea, las que proyectan las principales tendencias del derecho internacional hasta las que impulsan nuevas perspectivas de las relaciones comerciales internacionales, sin faltar por cierto la rica perspectiva que deriva de las experiencias históricas. 
Este volumen es más que un homenaje a tres generaciones. Es el testimonio de cuán valioso puede ser el aporte académico cuando se realiza de manera desinteresada e inspirada en los ideales de la creatividad y la independencia intelectual.

Francisco Orrego Vicuña (Not so old, not that young)

Director de Estudios Internacionales 